\title{
Interactions of the Autoxidized Products of Linoleic Acid with Enzyme Proteins
}

\author{
P. T. Gamage and Setsuro Matsushita
}

Research Institute for Food Science, Kyoto University

Received March 11, 1972

\begin{abstract}
$T_{1 .}$ winactivation of the enzyme protein by the autoxidized products of linoleic acid was studied with special reference to the incorporation of the autoxidized products into the protein and the consequent damage to the amino acid residues of the protein. Inactivation of ribonuclease (RNase) was due to the incorporation of linoleic acid hydroperoxides (LAHPO) or their secondary products (SP). Pepsin showed a lesser degree of inactivation and incorporation with respect to LAHPO, but SP activated the pepsin activity. Trypsin was affected only by SP. In RNase lysine, histidine, tyrosine, methionine and cystine were the most labile amino acids to LAHPO attack, while methionine was the only amino acid which suffered damage in trypsin and pepsin. The SP caused damage of methionine, lysine and histidine in RNase, methionine, cystine and histidine in trypsin and methionine and aspartic acid in pepsin. The reactions of LAHPO were enhanced by a prooxidant, ascorbic acid (AsA), while antioxidants acted otherwise. The incorporation of SP into RNase and pepsin was enhanced by AsA while antioxidants were ineffective.
\end{abstract}

Oxidation of unsaturated fatty acids leads to the formation of hydroperoxides and their secondary products such as aldehydes, ketones, acids, etc. Interactions of such compounds with proteins contribute to the destruction of their natural biological activities and hence cause toxicity to the biological system. With such considerations, several studies on the reactions of the autoxidized lipids with protein have been reported. ${ }^{1 \sim 6)}$ However, although the reaction conditions which were used seemed to be appropriate for determining the deterioration of food materials, they were too drastic to examine the toxic effects in biological systems. The primary stable products of autoxidation, the hydroperoxides, were generally considered to be the cause of toxicity in lipid oxidation in biological systems, but recently, emphasis has been laid on the toxicity of the secondary products. ${ }^{7 \sim 11}$, Therefore, it is important to determine such toxic effects with purified hydroperoxides and secondary products precisely and under

Abbreviations. LAHPO, linoleic acid hydroperoxides; SP, secondary products from LAHPO; RNase, ribonuclease; AsA, ascorbic acid; BHT, butyl hydroxy toluene. mild conditions. In the earlier investigation, ${ }^{12)}$ we showed that detectable changes were observed in enzyme activities with partially purified LAHPO at certain low concentrations. In the present study, the interactions of the autoxidized products of linoleic acid with proteins are investigated using pure LAHPO and SP (mixture) against RNase, trypsin and pepsin as model proteins. The reaction conditions were chosen to be as mild as possible in order to find the reaction mechanism of the autoxidized lipid products.

\section{MATERIALS AND METHODS}

Materials. Linoleic acid was purchased from Tokyo Kasei Co. and was used without further purification. Linoleic acid-1-14 C (specific activity $35 \mathrm{mCi} / \mathrm{mmole}$ ) was obtained from Daiichi Chem. Co.

Bovine pancreatic RNase( $5 x$-crystallized), bovine pancreatic trypsin( $2 x$-crystallized) and hog pepsin $(2 x-$ crystallized) were purchased from Sigma Chem. Co.

Preparation of the autoxidized products of linoleic acid. A solution containing $4 \mathrm{~g}$ of linoleic acid was spread as a thin film on the inner surface of a $100 \mathrm{ml}$ flasks by rotating at $37^{\circ} \mathrm{C}$ in air for $70 \mathrm{hr}$ using a rotary evaporator. LAHPO and SP were isolated from the 
reaction mixture by column chromatography as described in a previous paper, ${ }^{13)}$ using $20 \%$ methanol in benzene as an immobile solvent and $2 \%$ methanol in benzene as a mobile solvent. Ether was used to elute SP. The isolated LAHPO was further purified by preparative thin-layer chromatography, using $n$-hexane: diethyl ether: acetic acid $(60: 40: 1)$ as the solvent system. The LAHPO band, detected under UV light, were pealed off and recovered with methanol. The SP fraction was treated similarly to get a solution in methanol. The purity of the LAHPO preparation was confirmed by thin-layer chromatography, using silica gel $F_{254}$ (Merck) plates and the same solvent system. The concentration of LAHPO was determined by UV spectrophotometry ${ }^{14}$ and peroxide value. ${ }^{15}$, The concentration of $\mathrm{SP}$ was determined with respect to their aldehyde concentration ${ }^{16)}$ and were expressed as $\mathrm{mg}$ acetaldehyde/ml, even though the preparation was a complicated mixture.

On the preparation of the autoxidized products of linoleic acid-1 $-{ }^{14} \mathrm{C}, 0.1 \mathrm{mCi}$ of linoleic acid-1 $-14 \mathrm{C}$ was added to $2 \mathrm{mg}$ of carrier linoleic acid and was autoxidized for $70 \mathrm{hr}$. The separation, purification and determination of the autoxidized products followed the same procedures as described above.

Determination of enzyme activities. The routine method was used with a slight modification as described in our former paper. ${ }^{12}$

Incorporation of labeled LAHPO and SP into enzyme proteins. For determining the radioactivity incorporated into enzyme proteins, a certain volume of the reaction mixture was withdrawn and spotted on a thin layer plate (silica gel $F_{254}$, Merck) and developed with the same solvent system as described above. The unreacted LAHPO and SP were carried to the solvent front. The proteins left at the origin were scraped off, and the radioactivities incorporated into the proteins were counted in a liquid scintillation counter (Packard).

Amino acid analysis. Amino acid analysis was performed with an amino acid analyzer, Yanagimoto model LS-5S. The enzyme proteins were incubated with LAHPO or SP, and the reaction mixture was washed 2 times with chloroform and 3 times with diethyl ether. The intact samples (LAHPO or SP) or those bound to the proteins non-specifically may be extracted with such washing procedures. The washed protein solutions which were completely devoid of the washing solvents (affected by centrifugation, decantation and evaporation) were hydrolyzed with $6 \mathrm{~N} \mathrm{HCl}$ for $20 \mathrm{hr}$ at $100^{\circ} \mathrm{C}$, and aliquots of the hydrolysate equivalent to $0.2 \mathrm{mg}$ protein was used for analysis.

\section{EXPERIMENTAL AND RESULTS}

Inactivation of enzymes with LAHPO and SP
RNase was preincubated with LAHPO or SP. At specific intervals, inhibition of the enzyme activity was determined as percent inhibition taking the original activity as $100 \%$ (Fig. 1). The time course of inhibition increased up to $30 \mathrm{~min}$ of incubation,

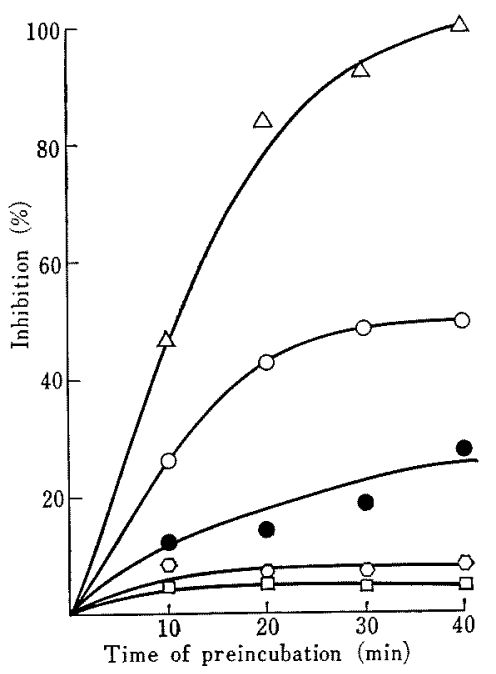

FIG. 1. Inactivation of RNase by LAHPO and SP. $0.1 \mathrm{ml}$ of RNase solution $(0.01 \mathrm{mg})$ was preincubated with $1.7 \mu$ moles of LAHPO or $2 \mu \mathrm{g}$ of SP and $1 \mathrm{ml}$ of $0.2 \mathrm{M}$ sodium acetate buffer, $\mathrm{pH} 5.0$ at $37^{\circ} \mathrm{C}$. At specific time intervals, the activity was determined. AsA, BHT, tryptophan and uric acid were added at a final concentration of $10^{-3} \mathrm{M}$ before the addition of LAHPO or SP. The effects of the added compounds on the activity are expressed as percent inhibition taking the original activity as $100 \%$.

O, LAHPO; $\square, \mathrm{LAHPO}+\mathrm{BHT} ; \triangle, \mathrm{LAHPO}+\mathrm{AsA}$; $\rightarrow$ LAHPO + tryptophan or uric acid (tryptophan and uric acid showed similar value); 0, SP

beyond which it gradually approached to a maximum. On the addition of AsA, the inhibition increased almost to completion, while BHT, tryptophan and uric acid had a remarkable effect on the reduction of inhibition of the activity. SP inhibited the activity to a lesser extent than in the case of LAHPO. Higher concentrations of SP were considered unproper as the higher concentrations produced intense turbidity. AsA or BHT had no appreciable influence on the activity of SP.

In the case of trypsin, LAHPO did not show any inhibitory effect on the activity (Fig. 2). But SP showed a remarkable 


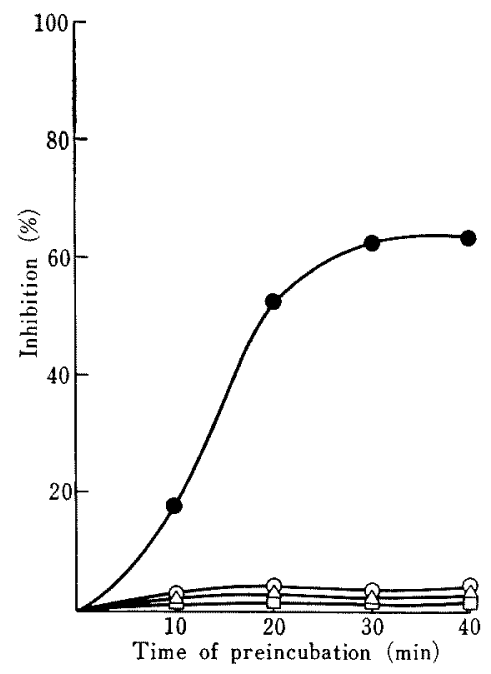

FIG. 2. Inactivation of Tryspin by LAHPO and SP. $0.1 \mathrm{ml}$ of trypsin solution $(0.2 \mathrm{mg})$ was preincubated with the same amount of LAHPO or SP as in Fig. 1 and $1 \mathrm{ml}$ of $0.2 \mathrm{M}$ Tris buffer, $\mathrm{pH} 8.0$ at $37^{\circ} \mathrm{C}$. The effects of AsA, BHT, tryptophan and uric acid on the inactivation were determined as in the case of RNase. The symbolic representations and results are expressed as in Fig. 1.

inhibition of the activity which was not affected by the addition of AsA or BHT.

LAHPO, under similar conditions as in the case of RNase, showed a similar pattern in the inhibition of pepsin activity but it was less remarkable (Fig. 3). The effects of AsA and BHT on the action of LAHPO showed similar pattern to RNase. SP, under similar conditions, had an activating effect on the activity of pepsin, which was uninfluenced by the addition of BHT while AsA inhibited the activity.

\section{Incorporation of $L A H P O$ and $S P$ into pro- teins}

Labeled LAHPO or SP was added to enzyme solutions and incubated. At certain intervals, the radioactivity incorporated into the enzyme protein was determined. In the case of RNase, the time course showed a relative increase in the incorporation (Fig. 4). AsA enhanced the incorporation remarkably while BHT reduced the incorporation significantly. A considerable incorporation was observed even after $2 \mathrm{~min}$ of the addition of

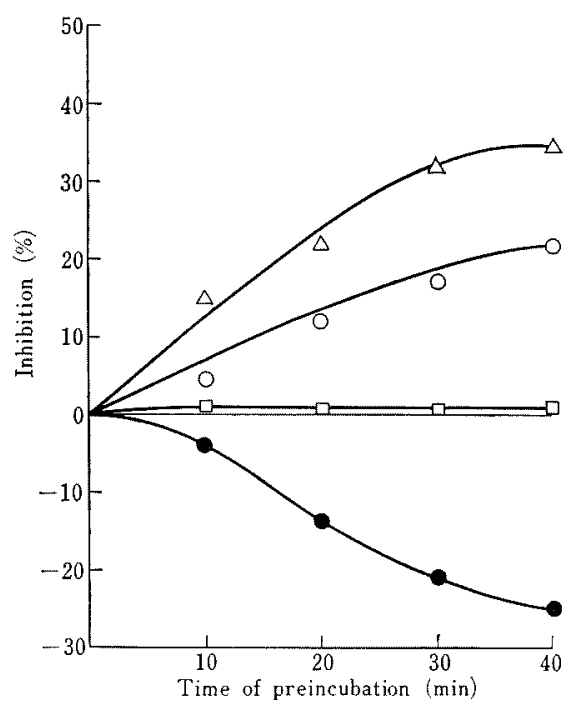

Fig. 3. Inactivation of Pepsin by LAHPO and SP. $0.1 \mathrm{ml}$ of pepsin solution $(0.2 \mathrm{mg})$ was preincubated with the same amount of LAHPO or SP and $1 \mathrm{ml}$ of $0.2 \mathrm{M}$ sodium acetate buffer, $\mathrm{pH} 5.0$ at $37^{\circ} \mathrm{C}$. The effects of AsA, BHT, tryptophan and uric acid on the inactivation were determined as in the case of RNase. The symbolic representations and results are expressed as in Fig. 1.

LAHPO. This may be attributed to the instantaneous non-specific adsorption of such compounds onto the protein. In the case of SP (Fig. 4), the time course did not show any significant effect on the incorporation. AsA under similar conditions showed a promoting effect on the incorporation of SP into RNase while BHT had no effect. The higher values observed at 2 min may be due to similar effect as in the case of LAHPO.

LAHPO had no significant incorporation into trypsin (Fig. 5). The presence of AsA in the reaction mixture showed a slight incorporation of LAHPO into trypsin, while BHT had no effect. With SP, a remarkable incorporation was observed which was uninfluenced by the addition of AsA or BHT.

The incorporation of LAHPO or SP into pepsin was much less distinctive compared with the incorporation of LAHPO or SP into RNase (Fig. 6). The effects of AsA or BHT on the activity of LAHPO showed a similar pattern to that of RNase. AsA had a considerable influence on the incorporation 


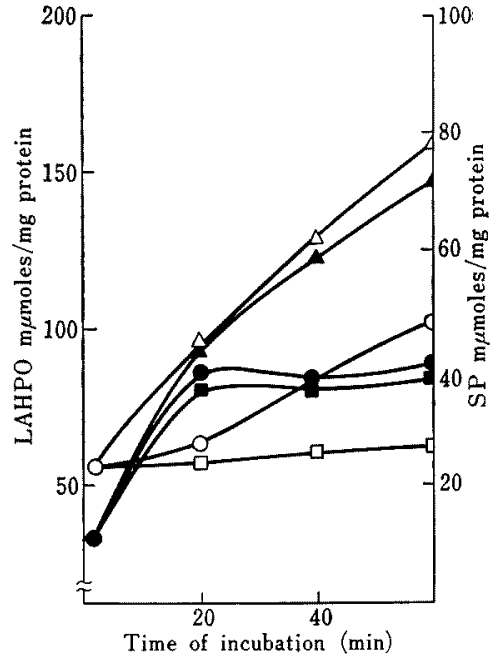

FIG. 4. Time Course of Incorporation of LAHPO and SP into RNase.

$0.05 \mathrm{ml}$ of LAHPO-1-14 C $(2.5 \mu$ moles, total $\mathrm{cpm}$ $25,000 /$ tube) solution or $0.01 \mathrm{ml}$ of $\mathrm{SP}(18 \mu \mathrm{g}$ as acetaldehyde, total $\mathrm{cpm} 85,000 /$ tube) solution was added to $1 \mathrm{ml}$ of RNase solution $(2 \mathrm{mg} / \mathrm{ml}$ of $0.2 \mathrm{M}$ sodium acetate buffer, $\mathrm{pH}$ 5.0) and was incubated at $37^{\circ} \mathrm{C}$. At time intervals as shown, $0.05 \mathrm{ml}$ was taken for counting. The effects of BHT and AsA on the incorporation of LAHPO or SP were determined by adding the compounds to the reacting medium at a final concentration of $10^{-3} \mathrm{M}$ before the addition of LAHPO or SP.

$O$, LAHPO; $\square, \mathrm{LAHPO}+\mathrm{BHT} ; \triangle, \mathrm{LAHPO}+\mathrm{AsA}$; $\bullet$, SP; $\mathbf{\square}, \mathrm{SP}+\mathrm{BHT} ; \boldsymbol{\Lambda}, \mathrm{SP}+\mathrm{AsA}$

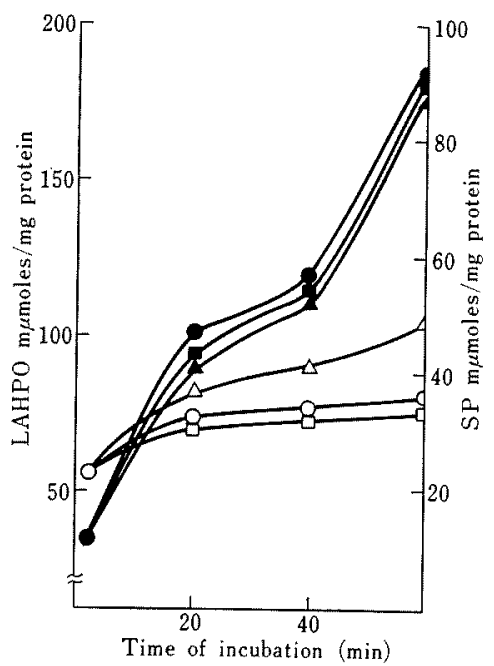

Fig. 5. Time Course of Incorporation of LAHPO and SP into Trypsin.

Assay conditions were the same as in RNase with the exception of the buffer used which was $0.2 \mathrm{M}$ Tris buffer, $\mathrm{pH}$ 8.0. The symbolic representations are the same as in Fig. 4.

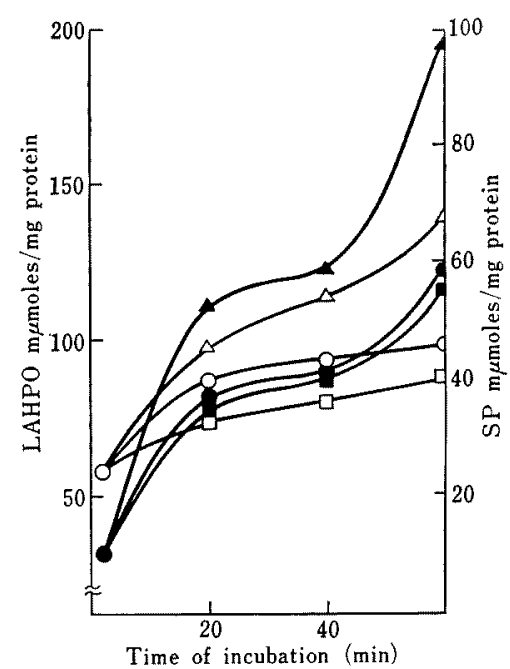

FIG. 6. Time Course of Incorporation of LAHPO and SP into Pepsin.

Assay conditions and the symbolic representations are the same as in Fig. 4.

of SP into pepsin while BHT was ineffective.

Damage to the amino acids of the enzyme protein by the interaction with LAHPO or $S P$

The enzyme proteins were incubated with LAHPO or SP and the unreacted samples or those bound to the protein non-specifically were washed with chloroform and diethyl ether. The washed proteins were hydrolyzed, and the amino acid composition was determined. The damage to the various amino acids were elucidated by comparing with the respective amino acid of the native protein. Table I shows the damage to the amino acids of RNase by LAHPO or SP. Lysine, histidine, tyrosine, methionine and cystine were the most labile amino acids to LAHPO attack while lysine, histidine and methionine were the amino acids which showed susceptibility to SP interaction. On the addition of AsA to the reaction mixture containing LAHPO, aspartic acid and glutamic acid in addition to the amino acids damaged only by LAHPO were affected. AsA, when added to the reaction mixture containing SP, damaged cystine in addition to histidine and methionine. 
Table I. Damage to the Amino Acids of RNASE BY THE INTERACTION WITH LAHPO OR SP

One milliliter of RNase solution $(10 \mathrm{mg} / \mathrm{ml}$ of $0.2 \mathrm{M}$ sodium acetate buffer, $\mathrm{pH} 5.0$ ) was incubated with $2.25 \mu$ moles of LAHPO or $65 \mu$ moles of SP at $37^{\circ} \mathrm{C}$ for $40 \mathrm{~min}$. At the end of incubation the protein solution was washed 2 times with $2 \mathrm{ml}$ portions of chloroform and 3 times with $2 \mathrm{ml}$ portions of diethyl ether and was hydrolyzed with $6 \mathrm{~N} \mathrm{HCl}$ at $100^{\circ} \mathrm{C}$ for $20 \mathrm{hr}$. An aliquot of the hydrolyzate equivalent to $0.2 \mathrm{mg}$ of protein was used for chromatographic analysis. On the determination of the effect of AsA on the activity of LAHPO, AsA was added to the reaction mixture at a final concentration of $10^{-3} \mathrm{M}$ before the addition of LAHPO.

\begin{tabular}{lrrrr}
\hline Amino acids & $\begin{array}{c}\text { RNase } \\
\text { LAHPO }\end{array}$ & $\begin{array}{c}\text { RNase } \\
\text { +AsA } \\
+ \text { LAHPO }\end{array}$ & $\begin{array}{c}\text { RNase } \\
+ \text { SP }\end{array}$ & $\begin{array}{c}\text { RNase } \\
+ \text { AsA } \\
+ \text { SP }\end{array}$ \\
\hline Aspartic acid & 0 & 49 & 0 & $\mathrm{~s}$ \\
Threonine & $\mathrm{s}$ & 10 & 0 & 11 \\
Serine & 0 & 0 & 0 & $\mathrm{~s}$ \\
Glutamic acid & 10 & 32 & 0 & $\mathrm{~s}$ \\
Proline & $\mathrm{s}$ & $\mathrm{s}$ & 0 & 0 \\
Glycine & $\mathrm{s}$ & 0 & 0 & 0 \\
Alanine & 0 & 0 & 0 & 0 \\
Valine & 0 & 0 & 0 & 0 \\
Half-cystine & 40 & 60 & $\mathrm{~s}$ & 24 \\
Methionine & 99 & 100 & 80 & 78 \\
Isoleucine & $\mathrm{s}$ & 17 & 17 & 14 \\
Leucine & 22 & 23 & 12 & 20 \\
Tyrosine & 62 & 70 & 17 & 22 \\
Phenylalanine & 0 & 0 & 0 & 0 \\
Lysine & 51 & 50 & 50 & 37 \\
Histidine & 54 & 37 & 49 & 47 \\
Arginine & $\mathrm{s}$ & $\mathrm{s}$ & $\mathrm{s}$ & $\mathrm{s}$ \\
\hline
\end{tabular}

$\mathrm{s}$, slight damage

* The \% amino acid loss was calculated using RNAse only as control.

Methionine was the only amino acid which showed lability to LAHPO in the case of trypsin while methionine, cystine and histidine were damaged by SP (Table II).

In the case of pepsin, only methionine showed to be affected by LAHPO, while aspartic acid in addition to methionine were damaged by SP. Addition of AsA to the reaction mixture containing $\mathrm{SP}$ showed no significant change in the activity of SP with respect to the damage to the amino acids of pepsin (Table III). Addition of AsA in
Table II. Damage to the Amino Acids of TRYPSIN BY THE INTERACTION WITH LAHPO OR SP

Assay conditions are the same as in RNase with the exception of the buffer used in the reaction medium was Tris buffer, $\mathrm{pH} 8.0$.

\begin{tabular}{lcc}
\hline \multicolumn{1}{c}{ Amino acids } & $\begin{array}{c}\text { Trypsin } \\
+ \text { LAHPO }\end{array}$ & $\begin{array}{c}\text { Trypsin } \\
+ \text { SP }\end{array}$ \\
\hline Aspartic acid & $\%$ amino acid loss* \\
Threonine & 0 & 0 \\
Serine & 14 & 17 \\
Glutamic acid & 0 & 0 \\
Proline & 0 & 14 \\
Glycine & 0 & $\mathrm{~s}$ \\
Alanine & $\mathrm{s}$ & 16 \\
Valine & 0 & 0 \\
Half-cystine & 0 & 12 \\
Methionine & 0 & 50 \\
Isoleucine & 83 & 89 \\
Leucine & 0 & $\mathrm{~s}$ \\
Tyrosine & 0 & $\mathrm{~s}$ \\
Phenylalanine & 0 & 20 \\
Lysine & $\mathrm{s}$ & 19 \\
Histidine & 0 & $\mathrm{~s}$ \\
Arginine & 12 & 42 \\
\hline
\end{tabular}

S, slight damage

* The \% amino acid loss was calculated using trypsin only as control.

the case of LAHPO, tyrosine and aspartic acid were damaged in addition to methionine. The determination of tryptophan in trypsin and pepsin was not performed as no change in tryptophan was observed by UV spectrophotometry. RNase does not contain tryptophan. ${ }^{18)}$

Changes in the absorption spectrum of $L A H P O$ and $S P$ on the addition of enzymes

LAHPO or SP had an absorption with a maximum at 233 or $230 \mathrm{~m} \mu$, respectively, as shown in Fig. 7. The addition of RNase decreased the peak intensity remarkably which was accompanied by a shift of the peak towards a longer wave length. The absorption spectrum of SP was less significantly affected by the addition of RNase. Under identical conditions as in the case of RNase with the exception of the difference in the buffer 
Table III. Damage to the Amino Acids of PEPSIN BY THE INTERACTION OF LAHPO OR SP

Assay conditions are the same as in RNase.

\begin{tabular}{|c|c|c|c|c|}
\hline Amino acids & $\begin{aligned} & \text { Pepsin } \\
+ & \text { LAHPO }\end{aligned}$ & $\begin{array}{c}\text { Pepsin } \\
+ \text { +AsA } \\
+ \text { LAHPO }\end{array}$ & $\begin{array}{l}\text { Pepsin } \\
+\mathrm{SP}\end{array}$ & $\begin{array}{l}\text { Pepsin } \\
+ \text { AsA } \\
+ \text { SP }\end{array}$ \\
\hline & \multicolumn{4}{|c|}{$\%$ amino acid loss $*$} \\
\hline Aspartic acid & 0 & 23 & 25 & 24 \\
\hline Threonine & 0 & s & s & $\mathrm{s}$ \\
\hline Serine & 0 & 0 & 0 & 14 \\
\hline Glutamic acid & 13 & s & 0 & 0 \\
\hline Proline & 0 & 0 & 0 & 0 \\
\hline Glycine & 0 & 0 & 0 & 0 \\
\hline Alanine & 0 & 0 & 0 & 0 \\
\hline Valine & 0 & 0 & 0 & 0 \\
\hline Half-cystine & s & $\mathrm{s}$ & 19 & 16 \\
\hline Methionine & 99 & 99 & 99 & 99 \\
\hline Isoleucine & 0 & 0 & 0 & 0 \\
\hline Leucine & 0 & 0 & 0 & 0 \\
\hline Tyrosine & 0 & 37 & s & 22 \\
\hline Phenylalanine & 0 & 0 & 0 & 0 \\
\hline Lysine & s & s & 22 & s \\
\hline Histidine & $\mathrm{s}$ & $\mathrm{s}$ & 0 & 0 \\
\hline Arginine & 13 & 12 & 0 & 11 \\
\hline
\end{tabular}

$\mathrm{s}$, slight damage

* The \% amino acid loss was calculated using pepsin only as control.

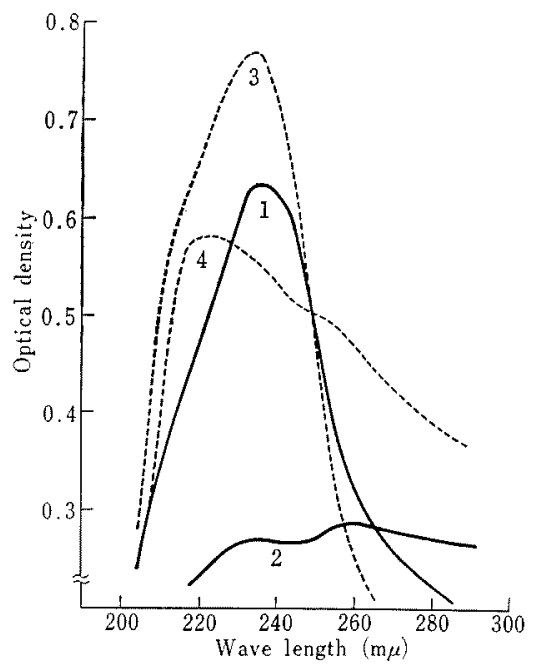

FIG. 7. Changes in the Absorption Spectrum of LAHPO or SP by the Addition of RNase.

1 , absorption spectrum of $1.4 \%$ moles of LAHPO in $2.5 \mathrm{ml}$ of $0.2 \mathrm{M}$ sodium acetate buffer, $\mathrm{pH} 5.0 ; 2$, on the addition of $0.1 \mathrm{ml}$ of the enzyme solution $(0.2 \mathrm{mg})$; 3 , absorption spectrum of $2 \mu \mathrm{g}$ of SP (as acetaldehyde) in $2.5 \mathrm{ml}$ of $0.2 \mathrm{M}$ sodium acetate buffer, $\mathrm{pH} 5.0 ; 4$, on the addition of $0.1 \mathrm{ml}$ of enzyme solution $(0.2 \mathrm{mg})$.

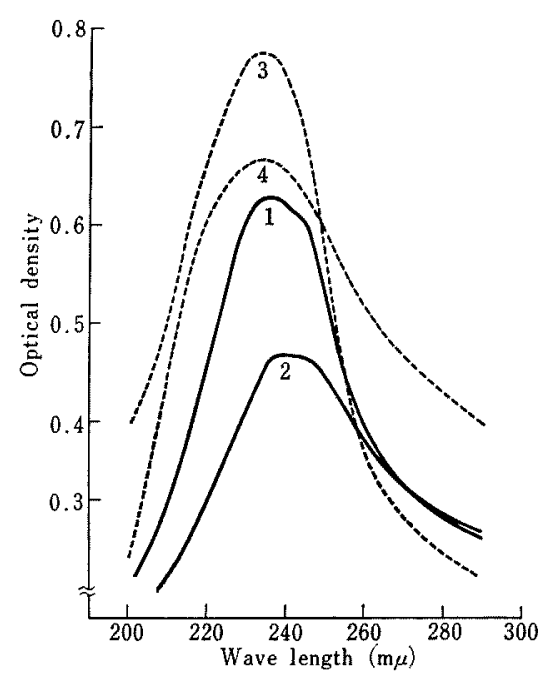

FIG. 8. Changes in the Absorption Spectrum of LAHPO or SP by the Addition of Trypsin.

Assay conditions were the same as in RNase with the exception of the buffer used was $0.2 \mathrm{M}$ Tris buffer, pH 8.0. Representations are the same as in Fig. 7.

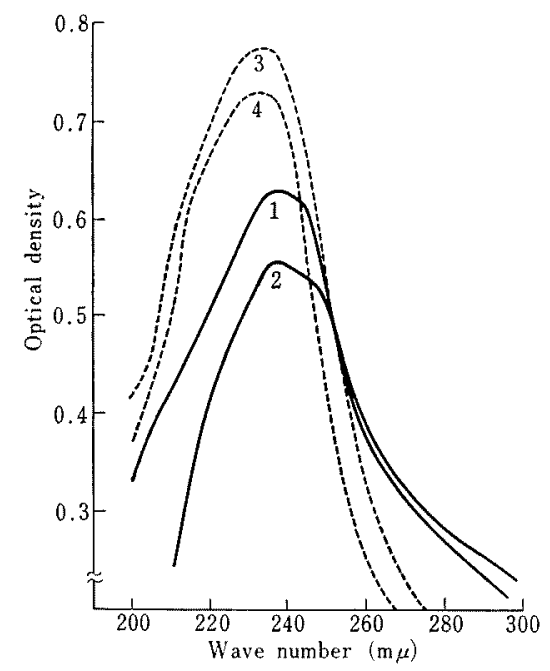

FIG. 9. Changes in the Absorption Spectrum of LAHPO or SP by the Addition of Pepsin.

Assay conditions and representations are the same as in Fig. 7.

used, a decrease in the intensities of the absorbance of LAHPO and SP was observed in the case of trypsin, but which was less significant. Shifts in the peaks were not significant (Fig. 8). Pepsin had no appreciable effects on the absorption spectrum of LAHPO or SP (Fig. 9). 


\section{DISCUSSION}

LAHPO used throughout in this study is pure and the methods used in determining the concentration may be considered to reveal almost exact values. The SP is a mixture of aldehydes, ketones and acids of shorter chain length, and under the conditions used in this study in determining the concentration of SP, it is obvious that the absolute values are not exact.

Comparison of the inhibition of enzyme activities with the incorporation of LAHPO or SP was considered to be appropriate, because it is probable that the inactivation is due to incorporation. The inactivation of RNase by LAHPO (Fig. 1) and the incorporation of LAHPO into RNase (Fig. 4) showed similar tendencies. The absorption spectrum of LAHPO almost disappeared by the addition of RNase (Fig. 7). AsA enhanced the inactivation of the enzyme by LAHPO and the incorporation of LAHPO into the enzyme, while the antioxidants, BHT, tryptophan ${ }^{19}$ ) and uric acid ${ }^{201}$ reacted otherwise. This observation favors the assumption that LAHPO reacts in a radical mechanism. The amino acids that showed to be damaged due to the reaction with LAHPO or the incorporation of LAHPO, and hence the responsible amino acids for the inactivation of the enzyme were lysine, histidine, tyrosine, methionine and cystine (Table I). The damage to the cystine residues can bring about conformational changes and inactivation of the enzyme. $^{21,22}$ Changes in the lysine and histidine residues which constitute the active site of RNase ${ }^{23.24}$ can inactivate the enzyme. The enhanced effect of AsA on the inactivation and incorporation may be attributed to the damage to aspartic acid and glutamic acid in addition to the amino acids damaged by LAHPO. By the methods used in this study, it is obvious that trypsin do not react much with LAHPO (Figs. 5 and 8), and hence a significant effect on the activity (Fig. 2) and considerable damage to amino acids
(Table II) can not be expected. The tendency of pepsin to react with LAHPO is much less than that of RNase (Figs. 3, 6 and 9), and only methionine showed to be affected (Table III). Considering the reactivity of LAHPO in a radical basis, it is probable that radicals attack different amino acids of the enzyme proteins and reactivity depends upon the surface exposition of such labile groups for the radical attack. Under the concentrations of the oxidized products used in this study, denaturation of the proteins may not be expected.

Inactivation of RNase by SP was comparatively weaker than that by LAHPO. The incorporation of SP into RNase and the effect on the absorption spectrum of SP afforded on the addition of RNase showed similar tendencies (Figs. 1, 4 and 7). The weaker tendency to interact was further evidenced by the lesser number of amino acids which showed lability to SP than to LAHPO (Table I). AsA, uric acid and tryptophan had no effect on the reactivity of SP with respect to inactivation (Fig. 1), but in the determination of the incorporation, AsA showed promoting effect while the antioxidants were ineffective (Fig. 4). SP showed a comparatively high tendency to react with trypsin as seen by the inactivation of trypsin (Fig. 2) and the incorporation of SP into trypsin (Fig. 5). Consequently, more amino acids, histidine and cystine, were damaged by SP than by LAHPO (Table II). The damage to the histidine residues can affect the inactivation of trypsin. ${ }^{25}$ The antioxidants or the prooxidants showed no effect on the activity of SP (Figs. 2 and 4). In the case of pepsin, SP showed an activating effect on the activity (Fig. 3) while the presence of AsA inhibited the activity. In the incorporation determination (Fig. 6), the tendencies were similar but less than in the case of RNase, and SP showed to affect only methionine and aspartic acid residues (Table III). The damage to aspartic acid residue may account for the observed loss in the activity. ${ }^{26)}$ The effect of AsA may be due to the activation of some 
compounds of SP in the acidic media (RNase and pepsin) which may be adsorbed to other amino acids non-specifically, other than those in the active site.

The non-specific adsorption of the fatty acids into proteins has been demonstrated..$^{27,28 \text {, }}$ The above discussion on the amino acid analysis is based on the assumption that the washing procedure prior to the hydrolysis ensures total elimination of the oxidized products. But there may exist a slight possibility that a small amount of the oxidized products which may be left unwashed even with non-polar solvents and bound non-specifically to the proteins may cause unspecific changes in the amino acid residues during acid hydrolysis.

From the foregoing discussion it can be deduced that the inactivation of RNase by LAHPO and SP is due to the incorporation of such oxidized products into the protein. LAHPO was more effective than SP in incorporating into RNase and consequently caused damage to more number of amino acid residues. The inactivation of trypsin by SP shows good relationship to incorporation and damage to amino acid residues. The incorporation of LAHPO into pepsin shows similar tendencies to inactivation while the behavior of SP was very different.

Using peroxidizing lipid-protein model systems, Tappel and his co-workers have shown polymerization of proteins ${ }^{()_{1}}$ and severe damage to most of the amino acids of the protein. ${ }^{3}$ But when LAHPO and SP in low concentrations are used as used in the present study, such drastic changes may not be expected.

From the differences observed in the incorporation, inactivation and relative damage to the amino acid residues with respect to LAHPO and SP, it was deduced that different amino acid residues are labile to be attacked by LAHPO and SP. Among the three enzymes under consideration, the structural conformations are different which result in differences of the surface exposed groups susceptible to be attacked by LAHPO and $\mathrm{SP}$, and such exposed groups are specific in their interactions with LAHPO and SP.
Acknowledgements. The authors express their thanks to Dr. T. Ogawa for his valuable discussions during this work. The authors are also indebted to Mr. T. Higasa for the technical assistance in the amino acid analysis.

\section{REFERENCES}

1) I. D. Desai and A. L. Tappel, J. Lipid Res., 4, 204 (1963).

2) F. Andrews, J. Bjorksten and F. B. Trenk, J. Am. Oil Chemists Soc., 42, 779 (1965).

3) W. T. Roubal and A. L. Tappel, Arch. Biochem. Biophys., 113, 5 (1966).

4) H. Buttks, J. Food Sci., 32, 432 (1967).

5) H. Little and P. J. O'Brien, Biochem. J., 106, 419 (1968).

6) C. Chio and A. L. Tappel, Biochemistry, 8, 2827 (1969).

7) E. Schauenstein, J. Lipid Res., 8, 417 (1967).

8) H. Kaunitz and C. A. Slanetz, J. Am. Oil Chemists Soc., 33, 630 (1966).

9) H. Kaunitz, Food Tech., 21, 278 (1967).

10) T. Miura, M. Kudo, M. Yoshida, K. Katano and K. Miyaki, J. Japan Oil Chemists Soc., 18, 726 (1969).

11) S. Yoshioka and H. Kaneda, "Toxicity of Autoxidized Oil," Symposium of Lipids on the Field of Nutrition and Foods, Fukuoka, Sept. 1971, No. 14.

12) S. Matsushita, M. Kobayashi and Y. Nitta, Agr. Biol. Chem., 34, 817 (1970).

13) P. T. Gamage, T. Mori and S. Matsushita, ibid., 35, 33 (1971).

14) P. J. O'Brien, Can. J. Biochent., 47, 485 (1969).

15) B. D. Sully, Analyst, 79, 86 (1954).

16) A. O. A. C., 11th edition, 1970, p. 150.

17) P. T. Gamage, T. Mori and S. Matsushita, Agr. Biol. Chem., 35, 1254 (1971).

18) D. J. Smyth, W. H. Stein and S. Moore, J. Biol. Chem., 238, 277 (1963).

19) R. Marcuse, J. Am. Oil Chemists Soc., 39, 97 (1962).

20) S. Matsushita, F. Ibuki and A. Aoki, Arch. Biochem. Biophys., 102, 446 (1963).

21) R. Setlow and B. Doyle, Biochim. Biophys. Acta, 24, 27 (1957).

22) R. Cecil and R. G. Wake, Biochem. J., 82, 401 (1962).

23) E. A. Barnard and W. D. Stein, J. Mol. Biol., 1, 339 (1959).

24) E. L. Smith, in "The Enzymes," ed. by P. D. Boyer, Vol. I, Academic Press, 1970, p. 288.

25) E. Gross and J. L. Morell, J. Biol. Chem., 241, 3638 (1966).

26) H. Neurath, R. A. Bradshaw and R. Arnon, in "Structure-Function Relationships of Proteolytic Enzymes," eds. by P. Desnuelle, et al., Munksgaard, Copenhagen, 1970, p. 113.

27) W. Kauzman, Adv. Protein Chem., 14, 1 (1959).

28) K. K. Fox, V. H. Holsinger, J. Chaha and M. J. Pallansch, J. Dairly Sci., 43, 1396 (1960). 